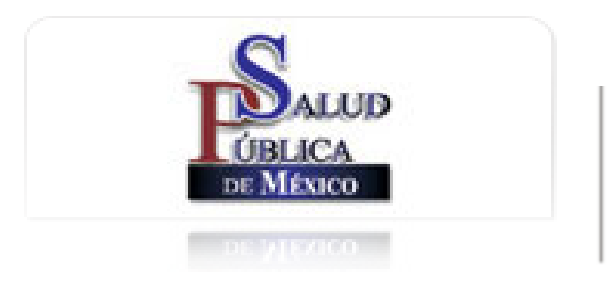

\section{Salud Pública de México}

ISSN: 0036-3634

spm@insp.mx

Instituto Nacional de Salud Pública

México

Mejía-Arango, Silvia; Wong, Rebeca; Michaels-Obregón, Alejandra

Normative and standardized data for cognitive measures in the Mexican Health and Aging Study

Salud Pública de México, vol. 57, núm. 1, 2015, pp. S90-S96

Instituto Nacional de Salud Pública

Cuernavaca, México

Available in: http://www.redalyc.org/articulo.oa?id=10638079013

How to cite

Complete issue

More information about this article

Journal's homepage in redalyc.org

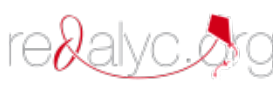

Scientific Information System

Network of Scientific Journals from Latin America, the Caribbean, Spain and Portugal

Non-profit academic project, developed under the open access initiative 


\section{Normative and standardized data for cognitive measures in the Mexican Health and Aging Study} Silvia Mejía-Arango, PhD, (1) Rebeca Wong, PhD, (2-4). Alejandra Michaels-Obregón, MS, MBA. ${ }^{(2,4)}$

\begin{abstract}
Mejía-Arango S, Wong R, Michaels-Obregón A. Normative and standardized data for cognitive measures in the Mexican Health and Aging Study. Salud Publica Mex 20I5;57 suppl I:S90-S96.
\end{abstract}

\begin{abstract}
Objective. To describe the cognitive instrument used in the Mexican Health and Aging Study (MHAS) in Mexican individuals aged 60 and over and to provide normative values for the Cross Cultural Cognitive Examination test and its modified versions (CCCE). Materials and methods. The CCCE was administered to 5120 subjects as part of a population-based sample free of neurologic and psychiatric disease from the MHAS 2012 survey. Normative data were generated by age and education for each test in the cognitive instrument as well as for the total cognition score. Pearson correlations and analysis of variance were used to examine the relationship of scores to demographic variables. Results. Results present standardized normed scores for eight cognitive domains: orientation, attention, verbal learning memory, verbal recall memory, visuospatial abilities, visual memory, executive function, and numeracy in three education groups within three age groups. Conclusion. These findings highlight the need for population-based norms for the CCCE, which has been used in population-based studies. Demographic factors such as age and education must be considered when interpreting the cognitive measures.
\end{abstract}

Key words: cognition; age; education; aging; Mexico
Mejía-Arango S, Wong R, Michaels-Obregón A. Normalización y estandarización de las medidas cognitivas en el Estudio Nacional de Salud y Envejecimiento en México. Salud Publica Mex 2015;57 supl I:S90-S96.

\section{Resumen}

Objetivo. Describir el instrumento cognitivo usado en el Estudio Nacional de Salud y Envejecimiento en México (Enasem) en personas mayores de 60 años,y proporcionar valores normativos para el Test Cognitivo Transcultural (CCCE, por sus siglas en inglés) y sus modificaciones. Material y métodos. Se administró el CCCE a 5120 individuos mayores de 60 años, libres de enfermedad neurológica y psiquiátrica de la Enasem 2012. Los datos normativos se obtuvieron para la puntuación en cada test incluido en el CCCE y para la puntuación total estratificando por edad y escolaridad. Para analizar la relación con las variables demográficas, se aplicaron la correlación de Pearson y el análisis de varianza. Resultados. Los resultados presentan normas estandarizadas para ocho dominios cognitivos: orientación, atención, aprendizaje verbal, memoria de evocación, habilidades espaciales, memoria visual, función ejecutiva y numerología en tres grupos de educación dentro de tres grupos de edad. Conclusión. Estos resultados subrayan la importancia de contar con datos normativos para los tests cognitivos que, como el CCCE, han sido aplicados en estudios poblacionales. Los factores demográficos como la edad y, en particular, la escolaridad deben considerarse al momento de interpretar las medidas aplicadas.

Palabras clave: cognición; edad; educación; envejecimiento; México

(I) Departamento de Estudios de Población, El Colegio de la Frontera Norte.Tijuana, Baja California, México.

(2) Sealy Center on Aging, The University of Texas Medical Branch. The United States.

(3) Preventive Medicine \& Community Health, The University of Texas Medical Branch. The United States.

(4) WHO/PAHO Collaborating Center on Aging and Health, The University of Texas Medical Branch. The United States.

Received on: March 12,2015 - Accepted on: April 8, 2015

Corresponding author: Dra. Silvia Mejía Arango. Departamento de Estudios de Población. El Colegio de la Frontera Norte. Carretera Escénica Tijuana-Ensenada km I8.5, San Antonio del Mar. 22560 Tijuana, Baja California, México.

E-mail:smejia@colef.mx 
$\mathrm{T}$ he Mexican Health and Aging Study (MHAS) started with the goal to prospectively evaluate the influence of disease on the health, function, and mortality of adults over the age of 50 in Mexico. A national representative panel of older adults born in 1951 or earlier was selected for the MHAS 2001 baseline, with two follow-ups in 2003 and 2012. In 2012, the study added a representative sample of the population from the 1952-1961 birth cohort. The MHAS data includes information on socioeconomic characteristics, migration, health conditions, disability, and family networks., ${ }^{1, *}$

One of the key health dimensions covered by the MHAS instruments is cognition. The core cognitive questionnaire used in the MHAS is the screening portion of the Cross Cultural Cognitive Examination (CCCE), a test designed by Glosser, Wolfe, Albert and colleagues in 1993 that has been proven independent of cultural and educational background. The instrument was selected to be used in the MHAS mainly because of its cross-cultural attributes. Concurrent validation of the test with respect to other well accepted screening instruments was determined. High specificity (>94\%) and sensitivity $(>99 \%)$ for detecting dementia were found in Guam and US mainland samples. ${ }^{2}$ To be meaningful, test scores must have an empirical frame of reference.

Standardized scores are used as part of neuropsychological assessments to evaluate cognitive impairment; they express the distribution of performance individuals can obtain on a particular test for a specific cognitive task. The resulting distribution of $Z$ scores has a mean of 0 and an SD of 1 regardless of the metric of raw scores from which they were derived. These normative reference groups are considered the 'gold standard' against which an individual's scores are compared, indicating whether the performance is impaired or intact. As well as facilitating the translation of raw scores to estimated population ranks, standardization of tests scores by virtue of conversion to a common metric facilitates comparison of scores across measures. It is important to highlight that the validity of normative standards depends heavily on an appropriate match between the individual being assessed and the normative data to which their test performance is compared. Furthermore, the definition of the norm group is a crucial factor in the accurate interpretation of norm-referenced scores. ${ }^{3,4}$

The present study aims to describe the cognitive instruments used in the MHAS and to provide normative data for the CCCE test and its modified versions. We do this by using a large, population-based sample strati-

\footnotetext{
* More details of the study are available on the study website in English (www.mhasweb.org) and in Spanish (www.enasem.org).
}

fied by age and education from the MHAS 2012 survey. We obtain normative data for each test in the cognitive instrument as well as for the total cognition score.

\section{Materials and methods}

This investigation was conducted using the responses to the MHAS 2012 survey cognition instrument, which was applied to study participants in-person, using paper and pencil, during interviews conducted through a household survey. The criteria for inclusion in the analytical sample for the present study were as follows: 1) interviewed directly as follow-up or as new subjects; 2) aged 60 years and older at the time of the 2012 interview; 3) without neurological disease as measured by the self-report of ever being diagnosed with a stroke; 4) without psychiatric disease as measured by a cut-point of 6 or more in the 9-item depression scale administered during the survey, and 5) completed all tests included in the Modified CCCE. Following these criteria, a total of 5120 participants were included in the present study. See figure 1 for a detailed summary of the MHAS 2012 sample and the resulting analytical sample after applying the inclusion criteria for the present study.

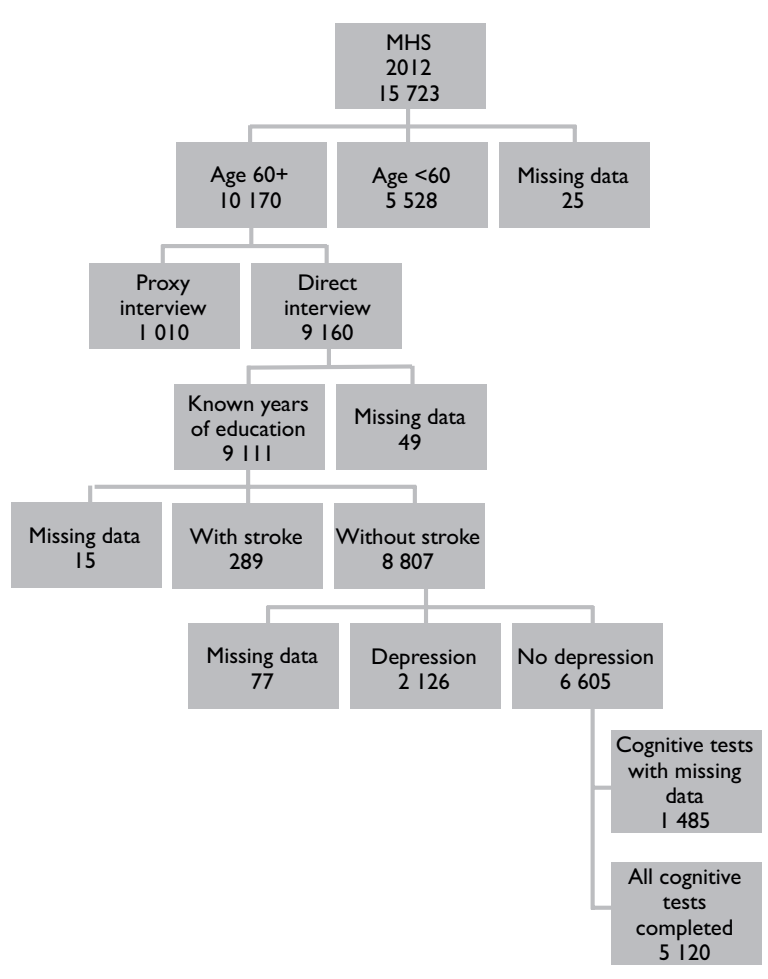

Figure I. FLOW Chart of the ANALytical SAMPLE SElection. MeXico, 2012 


\section{Cognitive measures in the MHAS waves}

Several modifications to the version of the CCCE used in the first MHAS wave (2001) were made in the second (2003) and third (2012) waves of the MHAS. The 2001 version permitted rapid assessment of four cognitive domains using adaptations of widely accepted mental status tests. It included items that evaluated: a) verbal memory (learning and recall), through an eight word list; b) visual-constructional abilities, through asking subjects to copy two figures in 90 seconds each; $\mathrm{c}$ ) visual memory, through recall of the two figures previously copied, and d) attention, through a visual scanning task in which the subject had to detect stimuli (up to 60) embedded among other similar stimuli in 60 seconds. The total score of the 2001 test ranged from 0 to 80 .

Because of the importance of measuring orientation to detect cognitive impairment, ${ }^{5}$ an additional cognitive domain was included in the 2003 wave. Three items measuring knowledge about the day, month and year were added, with the total score of the cognition tests ranging from 0 to 83. In the third wave (2012) two new domains measuring executive function and numeracy were added. Animal naming for one minute measured verbal fluency, which is considered an executive function test. ${ }^{6}$ A numeracy domain was measured through the task of counting backwards from 20 to 0 in a maximum time of 60 seconds. Numeracy is considered a test of working memory. ${ }^{7}$ The time spent by those who correctly completed the task was also recorded.

Another modification introduced in 2012 was in the visuospatial and visual memory tasks. In the first two waves, subjects had to copy two different figures and then recall them with only two possible scores for each task: (0) failed or (1) passed. Total score for visuospatial abilities and visual memory ranged from 0 to 2 . A more sensitive scoring system that captured different levels of difficulty was introduced in 2012 and only one figure was included. The tests included in each wave are summarized in table I. It is worth noting that the modifications to the instrument and the scoring system across the three waves of the study allow comparability across waves. For more details on the cognitive measures, see MichaelsObregón, Mejia-Arango and Wong. ${ }^{8}$ A total cognitive score on the CCCE for each wave was calculated by adding up the raw scores for each measure. The CCCE maximum total score is 80 for 2001 and 83 for 2003. For the 2012 wave, the raw scores of verbal fluency and the time to complete backwards counting were coded and summed according to the coded score (table II). The CCCE maximum total score for 2012 is 99.

\section{Statistical analysis}

Data analyses were conducted using SPSS version 19.0. Descriptive statistics (mean, standard deviation, percentages) are provided for demographic and health variables. Group differences were established using analysis of variance (anova) with Scheffe procedure for pairwise contrasts for the continuous variables and $c^{2}$ for categorical data. Finally, standardized normative scores for each measure were calculated stratifying subjects by three education levels $(0,1$ to 6 , and 7 or more years of education) within three age groups (60 to 69,70 to 79 , and 80 or more years of age). Raw scores for all measures in each of the nine groups (by age and by education) were converted to standardized scores ( $\mathrm{Z}$ scores) and then assigned to their corresponding raw scores with a mean of 0 and a standard deviation of 1 . Z scores for -1.5 and 1.5 standard deviations were also determined, due to the use of this criterion to classify mild cognitive impairment. ${ }^{9}$

Table I

\section{Structure of the modified CCCE for the MHAS waves. México, 200 I-20I 2}

\begin{tabular}{llll}
\multicolumn{1}{c}{ Cognitive domain } & Test description & $200 I$ & 2003 \\
Visuospatial abilities & Copy two figures* & $\checkmark$ & $\boldsymbol{V}$ \\
\hline Visual memory & Recall figures* & $\checkmark$ & $\boldsymbol{V}$ \\
\hline Verbal learning memory & Repeat eight word list during three trials & $\boldsymbol{V}$ & $\boldsymbol{V}$ \\
\hline Verbal recall memory & Free recall of eight word list & $\boldsymbol{V}$ & $\boldsymbol{V}$ \\
\hline Visual scanning & Visual scan of stimuli embedded & $\boldsymbol{V}$ \\
\hline Orientation & Day, month, year & & $\boldsymbol{V}$ \\
\hline Verbal fluency & Animals in 60 seconds & $\boldsymbol{V}$
\end{tabular}

In 2012, only one figure had to be copied and recalled 
Table II

RAW AND CODED SCORES FOR 2012 CCCE NeW MeAsures. MeXico

Coded score

\begin{tabular}{ll} 
Verbal fluency (number of animals) & \\
\hline $0-8$ & 1 \\
\hline $9-18$ & 2 \\
\hline $19-24$ & 3 \\
\hline $25-50$ & 4
\end{tabular}

Numeracy (time in seconds)

\begin{tabular}{ll}
$31-60$ & 1 \\
\hline $21-30$ & 2 \\
\hline $11-20$ & 3 \\
\hline $3-10$ & 4
\end{tabular}

\section{Results}

Demographic characteristics of the sample are presented in table III. Of the 5120 subjects in the analytical sample, $53 \%$ were women. The mean age of the sample was 68.6 years (SD 6.8), nearly two thirds of the elders were in the lowest age range (60-69 years), $29 \%$ were aged 70 to 79 years, and less than $10 \%$ were in the oldest old group (aged 80 and older). The average education in years was 6.1; however, the standard deviation of 4.6 is evidence of the large variance among subjects. More than $10 \%$ have no schooling, half of them attended school between 1 and 6 years, and one third of the sample had seven or more years of education. Although results are not shown, CCCE scores were weakly but significantly correlated with age, with values ranging from $r=-0.014$ to -0.32. In comparison, correlations with education were higher ( $r=0.26$ to 0.51$)$.

Although results are not shown, anova analysis by age and education showed significant differences $(p<0.00)$ between the three education groups within the age group 60-69. There is a pattern of increasing scores with increasing education level. Elders aged 70 to 79 years also showed the same pattern, although performance in recall memory was not different between the lowest education groups (0 years and 1-6 years). However, in the oldest old, differences were not apparent among several tests between the lowest education groups (e.g., verbal learning memory, memory recall, verbal fluency) and between the mid and highest education groups (memory recall, visual memory, orientation).

Tables IV, V and VI present the total standardized normative score of the modified CCCE for three education levels ( 0,1 to 6 , and 7 or more years of education)
Table III

\section{Demographic Characteristics AND COGNITIVE Performance. MeXico, 2012}

Variables

Min - Max Descriptives \%, Mean (SD)

Sex: female

$52.7 \%$

\begin{tabular}{|c|c|c|}
\hline Age: years & $60-110$ & $68.6(6.8)$ \\
\hline 60 to 69 & & 62.5 \\
\hline 70 to 79 & & 29.2 \\
\hline 80 and more & & 8.3 \\
\hline
\end{tabular}

\begin{tabular}{|c|c|c|}
\hline Education: years & $0-21$ & $6.1(4.6)$ \\
\hline 0 years & & II.I \\
\hline $1-6$ years & & 55.8 \\
\hline 7 and more years & & 33.1 \\
\hline
\end{tabular}

\begin{tabular}{lcc} 
Orientation & $0-3$ & $2.6(0.7)$ \\
\hline Verbal learning memory & $0-8$ & $4.8(\mathrm{I} .2)$ \\
\hline Verbal recall memory & $0-8$ & $4.4(\mathrm{I} .9)$ \\
\hline Visual scanning & $0-60$ & $28.3(\mathrm{I} 4.5)$ \\
\hline Visuospatial abilities & $0-6$ & $5.6(0.9)$ \\
\hline Visual memory & $0-6$ & $4.8(\mathrm{I} .6)$ \\
\hline Verbal fluency & $0-35$ & $15.3(4.8)$ \\
\hline Numeracy & $3-60$ & $10.3(6.6)$
\end{tabular}

within three age groups (60 to 69,70 to 79 , and 80 or more years of age), for each wave (2001, 2003 and 2012). The tables present raw scores of each measure in the columns and the standardized value ( $Z$ value) to which it corresponds in the columns at the beginning and end of the table. Scores in the normal range correspond to a $Z$ value of 0 with one standard deviation up +1 and down -1 . The number of standard deviations above this range represent high levels of performance: normal high (1.5), high (2.0), and superior (3). Those below the normal range show different levels of impairment that can be classified as mild (-1.5), moderate (-2.0), and severe (-3.0). Considering that the changes introduced across the three waves of the study yield a total score of the cognition instrument that is different for each wave, we performed a similar exercise for the two previous waves.*

\footnotetext{
* Additional analyses were completed to determine the standardized normative scores of the modified 2012 CCCE for the same three education levels, within the three age groups (60 to 69, 70 to 79 , and 80 or more years of age), for each cognitive domain: visuospatial abilities, visual memory, verbal learning memory, verbal recall memory, visual scanning, orientation, verbal fluency, and numeracy. The results are available for download at https:// www.dropbox.com/s / 8t273dt2vu9yril/Normative $\% 20$ and $\% 20$ Standardized $\% 20$ data $\% 20$ for $\% 20$ Cognition $\% 20$ measures $\% 20$ in $\% 20$ the $\% 20$ MHAS- $\% 20$ Additional $\% 20$ Tables.pdf?dl $=0$
} 
Table IV

Norms for total scores in participants during 200 I wave ( $=4$ 348). Mexico

\begin{tabular}{|c|c|c|c|c|c|c|c|c|c|c|}
\hline & & & & & 2001 & & & & & \\
\hline Z & & 60 to 69 years & & & 70 to 79 years & & & and more ye & & Z \\
\hline Score & 0 educ & I to 6 educ & $7+$ educ & 0 educ & I to 6 educ & $7+$ educ & 0 educ & I to 6 educ & $7+$ educ & Score \\
\hline 3 & $63-80$ & $73-80$ & & $55-80$ & $58-80$ & $79-80$ & $63-80$ & $67-80$ & $78-80$ & 3 \\
\hline 2.0 & $53-62$ & $63-72$ & $77-80$ & $46-54$ & $56-67$ & $73-78$ & $47-48$ & $51-63$ & $60-68$ & 2.0 \\
\hline 1.5 & $48-52$ & $58-62$ & $72-76$ & $4 \mid-45$ & $51-55$ & $67-72$ & $38-44$ & $45-50$ & $55-59$ & 1.5 \\
\hline I & $41-47$ & 50-57 & 64-7I & $35-40$ & $43-50$ & $59-66$ & $30-37$ & $37-44$ & $48-54$ & I \\
\hline 0 & $24-40$ & $31-49$ & $46-63$ & $20-34$ & $25-42$ & $39-58$ & $15-29$ & $19-36$ & $30-47$ & 0 \\
\hline-1 & $17-23$ & $23-30$ & $38-45$ & $14-19$ & I8-24 & $30-38$ & 8-14 & $11-18$ & $23-29$ & -1 \\
\hline-1.5 & $12-16$ & $18-22$ & $32-37$ & $10-13$ & $13-17$ & $24-29$ & $4-7$ & $5-10$ & $17-22$ & -1.5 \\
\hline-2.0 & $4-11$ & $8-17$ & $|8-3|$ & $7-8$ & $5-12$ & $9-23$ & $0-3$ & $0-4$ & $9-16$ & -2.0 \\
\hline-3.0 & $0-3$ & $0-7$ & $0-17$ & $0-6$ & $0-4$ & $0-6$ & & & $0-8$ & -3.0 \\
\hline
\end{tabular}

Table $\mathbf{V}$

Norms for total scores in participants during 2003 wave (n=4 237). Mexico

\begin{tabular}{|c|c|c|c|c|c|c|c|c|c|c|}
\hline & & & & & 2003 & & & & & \\
\hline$z$ & & 60 to 69 years & & & 70 to 79 years & & & and more yea & & Z \\
\hline Score & 0 educ & I to 6 educ & $7+$ educ & 0 educ & I to 6 educ & $7+$ educ & 0 educ & I to 6 educ & $7+$ educ & Score \\
\hline 3 & $69-83$ & $79-83$ & & $56-83$ & $72-83$ & & $53-83$ & $66-83$ & $72-83$ & 3 \\
\hline 2.0 & $57-68$ & $66-78$ & $81-83$ & $49-51$ & $59-7 \mid$ & $76-83$ & $45-51$ & $54-65$ & $65-71$ & 2.0 \\
\hline 1.5 & $51-55$ & $60-65$ & $75-80$ & $44-48$ & $53-58$ & $70-75$ & $4 \mid-44$ & $48-53$ & $57-62$ & 1.5 \\
\hline I & $44-50$ & 53-59 & $67-74$ & $37-42$ & $46-52$ & $62-69$ & $33-40$ & $40-47$ & $50-56$ & I \\
\hline 0 & $26-43$ & $34-52$ & $48-66$ & $22-36$ & $28-45$ & $4|-6|$ & $16-32$ & $21-39$ & $32-49$ & 0 \\
\hline-1 & $19-25$ & $26-33$ & $4 \mid-47$ & $|6-2|$ & $21-27$ & $33-40$ & $10-15$ & $13-20$ & $25-30$ & -1 \\
\hline-1.5 & $14-18$ & $21-25$ & $35-40$ & $12-15$ & $15-20$ & $26-32$ & $7-11$ & $7-12$ & $20-24$ & -1.5 \\
\hline-2.0 & $5-13$ & $9-20$ & $22-34$ & $8-11$ & $6-14$ & $12-25$ & $0-6$ & $4-6$ & $12-18$ & -2.0 \\
\hline-3.0 & $0-4$ & $0-8$ & $0-21$ & $0-7$ & $0-5$ & $0-11$ & & $0-3$ & $0-11$ & -3.0 \\
\hline
\end{tabular}

Table Vı

Norms for total scores in participants during 20 I 2 waVe ( $N=5$ I 20). Mexico

\begin{tabular}{|c|c|c|c|c|c|c|c|c|c|c|}
\hline & & & & & 2012 & & & & & \\
\hline$z$ & & 60 to 69 years & & & 70 to 79 years & & & and more yec & & $Z$ \\
\hline Score & 0 educ & I to 6 educ & $7+$ educ & 0 educ & I to 6 educ & $7+$ educ & 0 educ & I to 6 educ & $7+$ educ & Score \\
\hline 3 & $83-99$ & $92-99$ & & $74-99$ & $87-99$ & & $67-99$ & $80-99$ & $83-99$ & 3 \\
\hline 2.0 & $70-82$ & $80-91$ & $95-99$ & $60-70$ & $73-86$ & $92-99$ & $59-66$ & $67-79$ & $77-82$ & 2.0 \\
\hline 1.5 & $64-69$ & $74-79$ & $89-94$ & $55-59$ & $67-72$ & $84-91$ & $54-58$ & $60-66$ & $71-75$ & 1.5 \\
\hline$I$ & $61-63$ & $66-73$ & $81-88$ & $48-54$ & $58-66$ & $75-83$ & $46-53$ & $51-59$ & $63-70$ & 1 \\
\hline 0 & $38-60$ & $46-65$ & $62-80$ & $34-47$ & $39-57$ & $54-74$ & $26-44$ & $32-50$ & $44-62$ & 0 \\
\hline-1 & $30-37$ & $38-45$ & $54-61$ & $26-33$ & $31-38$ & $45-53$ & $19-25$ & $23-31$ & $36-43$ & -1 \\
\hline-1.5 & $25-29$ & $31-37$ & $48-53$ & $22-25$ & $25-30$ & $4 \mid-44$ & $12-17$ & $17-22$ & $30-35$ & -1.5 \\
\hline-2.0 & $15-23$ & $13-30$ & $33-47$ & $|3-2|$ & $12-24$ & $23-38$ & $0-11$ & $13-16$ & $18-25$ & -2.0 \\
\hline-3.0 & $0-9$ & $0-12$ & $0-25$ & $0-12$ & $0-11$ & $0-22$ & & $0-10$ & $0-17$ & -3.0 \\
\hline
\end{tabular}




\section{Discussion}

The present study aimed to provide standardized reference norms for the Cross Cultural Cognitive Examination Test (CCCE) and its modified version used in the Mexican Health and Aging Study (MHAS) in Mexican individuals aged 60 and over. The result tables present standardized normed scores for eight cognitive domains: orientation, attention, verbal learning memory, verbal recall memory, visuospatial abilities, visual memory, executive function, and numeracy in three education groups within three age groups. When measuring cognitive functioning in survey studies, three issues need to be considered, all of which were confirmed by the results: a) Cognitive structure is multidimensional, as shown by the results, with subjects presenting variation across the multiple domains; $b$ ) Declines in cognitive function with age are not uniform, either within or across cognitive domains, and the results again confirm the expectation, showing heterogeneity in the age declines, and c) Decline in cognitive abilities show inter-individual variability. Multidimensionality of cognitive structure is measured in the CCCE through seven domains, which guarantees a comprehensive analysis of the elders' cognitive status. For example, the ability to learn and retain new information is probably the most widely recognized cognitive consequence of aging. Both measures (verbal learning and recall memory) follow a different decline gradient with age ${ }^{10}$ and may predict different levels of a person's need for assistance with basic activities of daily living. ${ }^{11}$ Furthermore, the nature of the change that occurs, the point at which changes become apparent, and the magnitude and rate of change vary, depending upon the cognitive domain in question. In general, researchers have explained the changes in cognition through an overall cognitive decline due to slowing of processing speed, ${ }^{12}$ diminished attention resources, and reduced working memory capacity. ${ }^{13}$ Another approach focuses on specific domains. Within a cognitive spectrum, they vary from high to low sensitivity to age: a) learning and memory; b) executive function abilities; c) language; d) visual-spatial abilities, and e) sustained attention. ${ }^{14}$ Changes in cognition may begin very early in life. However, the differences may be too small to measure until the study subjects have reached older ages. For some researchers, significant age-related decline is not normative until after age 60 on most ability measures; however, there are wide individual differences in rates of change trajectories in midlife. Looking retrospectively over the association of these trajectories during midlife with subsequent functioning in old age, it has been reported that subjects who showed decline in old age had low performance in memory, verbal flu- ency, and psychomotor speed in midlife, while declines in reasoning, spatial orientation, and vocabulary were not precursors of impairment. ${ }^{15}$

The standardized normed scores presented in this paper will permit the study of cognitive decline in the participants of a large national sample followed up to study the aging process in Mexicans, and how cognitive impairment is associated with a variety of health, economic, and social outcomes. Cognitive profiles at different periods of time may be studied by monitoring the changes among the different domains as well. The results of our analysis show that cognitive abilities have great inter-individual variability. Although the average score on many neuropsychological tests is lower among the older than the younger subjects, there is more variability in the older age group. It has been suggested that there are subtypes of "stables", "decliners" and "gainers" in terms of memory performance in middle age. ${ }^{15}$ Individual differences in decline have been explained by the presence of risk factors such as education, race, gender, smoking, apolipoprotein E4 alleles, reduced hippocampus volume, co-morbid chronic diseases, as well as by protective factors: high levels of education, environmental complexity, nature of work, cognitive engagement, and physical exercise. ${ }^{16}$

The CCCE standardized normed scores provide data by age, which is the most important risk factor for cognitive impairment; and for education levels, which is one of the biggest sources of variability in cognitive performance, in addition to being a key risk factor in the Mexican population of older adults, with a large share of illiterate elders. ${ }^{17}$

The standardized scores present several advantages for researchers. The norms serve to convert raw scores to a common metric and facilitate comparison of scores across different cognitive measures. Despite these virtues, it is necessary to consider the limitations of the present study. First, there is ongoing debate about what constitutes the "best" normative comparison group for neuro-cognitive tests, with some authors advocating that screening out common illnesses results in "supernormal" samples that may not represent the general population. We did not address this issue, but presented community-based population norms and excluded subjects with major neurologic and psychiatric symptoms, which are known to affect cognitive performance. ${ }^{18}$ Second, we did not present cut-off points separately by gender. There were no meaningful gender differences in the results (not shown and available upon request); thus, we opted to present the results with both genders together. Future analysis with larger samples may support the calculation of cut-off points stratified by gender. 
Finally, our results also point to several possible avenues of future research. The lack of association between education and cognition at older ages deserves further exploration, since this well-established pattern of associations is a key indicator of health and mortality differentials. In addition, it would be informative to identify how much of the overall convergence of cognitive scores at older ages is due to particular domains and to establish if all domains converge at similar rates.

\section{Acknowledgments}

The MHAS is supported by the National Institutes of Health / National Institute on Aging (R01AG018016) and by the Instituto Nacional de Estadística y Geografía (INEGI) in Mexico. The MHAS study protocol and instruments were reviewed and approved by the Institutional Review Board or Ethics Committee of the University of Texas Medical Branch, the INEGI in Mexico, and the Instituto Nacional de Salud Pública (INSP) in Mexico. This work was supported by the Sealy Center on Aging at the University of Texas Medical Branch. We appreciate the assistance of Brian Downer with the content analysis. We also acknowledge comments from Alberto Palloni and Sarah Toombs to an earlier version of this article.

Declaration of conflict of interests. The authors declare that they have no conflict of interests.

\section{References}

I. Wong R, Michaels-Obregon A, Palloni A. Cohort profile: the Mexican Health and Aging Study (MHAS). Int J Epidemiol 2015 Jan 27. doi: 10.1093/ ije/dyu263.

2. Wolfe N, Imai Y, Otani C, Nagatani H, Hasegawa K, Sugimoto K, et al. Criterion validity of the cross-cultural cognitive examination in Japan. J Gerontol 1992;47:289-291.

3. Slick DJ. Psychometrics in neuropsychological assessment. In: Strauss E, Sherman E, Spreen O, eds. A compendium of tests: administration, norms and commentary. New York: Oxford University Press, 2006:3-43.
4. Harrison J, Minassian SL, Jenkins L, Black RS, Koller M, Grundman M.A neuropsychological test battery for use in Alzheimer disease clinical trials. Arch Neurol 2007;64(9):1323-1329.

5. Cullen B, O'Neill B, Evans J], Coen RF, Lawlor BA.A review of screening tests for cognitive impairment. J Neurol Neurosurg Psychiatry 2007;78(8):790-799.

6. Kips CM, Hodges JR. Cognitive assessment for clinicians. J Neurol Neurosurg Psychiatry 2005;76(suppl I):i22-i30.

7. Logie RH, Gilhooly KJ,Wynn V. Counting on working memory in arithmetic problem solving. Mem Cognit 1994;22(4):395-4I0.

8. Michaels-Obregón A, Mejía-Arango S,Wong R. The Mexican Health and Aging Study: Cognitive Functioning Measures, Version 2 [online document] [accessed on July 2014]. Available at: http://www.mhasweb.org/DiscussionForum/File\%20Upload/Documents/Mexican\%20Health\%20and\%20 Aging\%20Study\%20(MHAS)\%20-\%20Cognition\%20Battery\%20(v2).pdf 9. Schinka JA, Loewenstein DA, Raj A, Schoenberg MR, Banko JL, Potter H, Duara R. Defining mild cognitive impairment: impact of varying decision criteria on neuropsychological diagnostic frequencies and correlates.Am J Geriatr Psychiatry 20 10;18(8):684-69l.

I0. Troyer AK, Häfliger A, Cadieux MJ, Craik FI. Name and face learning in older adults: effects of levels of processing, self-generation and intention to learn.J Gerontol B Psychol Sci Soc Sci 2006;6I(2):P67-P74.

II. Cavallini E, Pagnin A,Vecchi T.Aging and everyday memory: the beneficial effect of memory training. Arch Gerontol Geriatr 2003;37(3):24I-257. 12. Salthouse TA. The processing-speed theory of adult age differences in cognition. Psychol Rev 1996; 103(3):403-428.

13. Hogan MJ, Kelly CA, Craik FI.The effects of attention switching on encoding and retrieval of words in younger and older adults. Exp Aging Res 2006;32(2):153-183.

14. La Rue A, Swanda R. Neuropsychological Assessment. In: Nussbaum PD, ed. Handbook of neuropsychology and aging. New York: Plenum Press, 1997. 15. Willis SL, Schaie KW. Cognitive trajectories in midlife and cognitive functioning in old age. In:Willis SL, Martin M, eds. Middle adulthood: a lifespan perspective. Thousand Oakes: Sage, 2005.

16. Petersen RC, Negash S. Mild cognitive impairment: an overview. CNS Spectr 2008; I3(I):45-53.

17. Mejia-Arango S, Gutierrez LM. Prevalence and incidence rates of dementia and cognitive impairment no dementia in the Mexican population: data from the Mexican Health and Aging Study. J Aging Health 20II;23(7):I050-1074.

18. Mitrushina M, Boone KB, Razani J, D'Elia LF, ed. Handbook of normative data for neuropsychological assessment. New York: Oxford University Press, 2005:3-II. 